\title{
Effect of composite surface treatment and aging on the bond strength between a core build-up composite and a luting agent
}

\author{
Caroline COTES', Mayra CARDOSO², Renata Marques de MELO'1, Luiz Felipe VALANDRO', Marco Antonio BOTTINO'
}

1- Department of Dental Materials and Prosthodontics, Institute of Science and Technology, UNESP - Univ. Estadual Paulista, São José dos Campos, SP, Brazil. 2- University Veiga de Almeida, UVA, Rio de Janeiro, RJ, Brazil.

\begin{abstract}
Corresponding address: Renata Marques de Melo - Departamento de Materiais Odontológicos e Prótese - Instituto de Ciência e Tecnologia, Escola de Odontologia - UNESP - Univ. Estadual Paulista - Av. José Longo, 777 - 12245-000 - São Dimas - São José dos Campos - SP - Brazil - e-mail: marquesdemelo@ gmail.com
\end{abstract}

Submitted: March 12, 2014 - Modification: October 3, 2014 - Accepted: November 18, 2014

\section{ABSTRACT}

\begin{abstract}
bjective: The purpose of this study was to assess the influence of conditioning methods and thermocycling on the bond strength between composite core and resin cement. Material and Methods: Eighty blocks $(8 \times 8 \times 4 \mathrm{~mm})$ were prepared with core build-up composite. The cementation surface was roughened with 120-grit carbide paper and the blocks were thermocycled $\left(5,000 \mathrm{cycles}\right.$, between $5^{\circ} \mathrm{C}$ and $55^{\circ} \mathrm{C}$, with a $30 \mathrm{~s}$ dwell time in each bath). A layer of temporary luting agent was applied. After $24 \mathrm{~h}$, the layer was removed, and the blocks were divided into five groups, according to surface treatment: (NT) No treatment (control); (SP) Grinding with 120-grit carbide paper; (AC) Etching with $37 \%$ phosphoric acid; (SC) Sandblasting with $30 \mu \mathrm{m} \mathrm{SiO}$ particles, silane application; (AO) Sandblasting with $50 \mu \mathrm{m} \mathrm{Al}_{2} \mathrm{O}_{3}$ particles, silane application. Two composite blocks were cemented to each other $(n=8)$ and sectioned into sticks. Half of the specimens from each block were immediately tested for microtensile bond strength $(\mu \mathrm{TBS})$, while the other half was subjected to storage for 6 months, thermocycling $\left(12,000\right.$ cycles, between $5^{\circ} \mathrm{C}$ and $55^{\circ} \mathrm{C}$, with a dwell time of $30 \mathrm{~s}$ in each bath) and $\mu$ TBS test in a mechanical testing machine. Bond strength data were analyzed by repeated measures two-way ANOVA and Tukey test $(\alpha=0.05)$. Results: The $\mu$ TBS was significantly affected by surface treatment $(p=0.007)$ and thermocycling $(p=0.000)$. Before aging, the SP group presented higher bond strength when compared to NT and AC groups, whereas all the other groups were statistically similar. After aging, all the groups were statistically similar. SP submitted to thermocycling showed lower bond strength than SP without thermocycling. Conclusion: Core composites should be roughened with a diamond bur before the luting process. Thermocycling tends to reduce the bond strength between composite and resin cement.
\end{abstract}

Keywords: Composite resins. Aging. Cementation.

\section{INTRODUCTION}

The clinical success of indirect restorations in teeth with excessive loss of tooth structure represents a challenge for dentists, as this situation results in a reduction in the ability of the tooth to resist multiple intraoral forces ${ }^{17}$. Depending on the extent of coronal destruction, intra-canal anchorage, followed by a core build-up, might be necessary. Pre-fabricated fiber posts and composite resin used as a core material have been indicated for this ${ }^{7}$

Ceramic crowns luted with resin cement on cores made of composite resin have greater fracture resistance than other materials used for the same purpose $^{26}$. The adhesive luting of ceramic crowns increases the fracture resistance of the core/crown complex ${ }^{25}$, and the adhesion between the materials is very important for long-term clinical success ${ }^{7}$. There are reports regarding the adhesion between post and luting agent ${ }^{5}$, a post and core material ${ }^{29}$ and luting agent and crown $^{1}$, but we could not 
find any studies regarding the adhesion between composite core material and luting agent or any protocols to improve such interfacial adhesion. This information is very important from a clinical standpoint, because adhesive luting to such substrate is a common clinical procedure.

The compositions of resin luting cements and composite resins used for making cores are chemically similar ${ }^{28}$. When a resin luting agent is used for prosthetic cementation to teeth, an interaction occurs between the luting agent and the surface layer of uncured adhesive applied to the dental substrate ${ }^{13}$. When the core build-up is made of composite resin, there should be an interaction between this material and the luting agent, however, the surface of the core composite is often completely cured and contaminated by saliva and temporary luting agents ${ }^{28}$. Several studies have discussed several ways to improve adhesion to contaminated and polymerized composite resin in order to improve the adhesion of composite repair, including: acid treatment and adhesive application $6,18,20,23$; grinding with diamond bur ${ }^{6,12,21}$; silicatization and silanization ${ }^{18,21,23}$; air abrasion with aluminum oxide particles and silanization ${ }^{6,12}$; and cleaning with pumice ${ }^{20}$. It should be emphasized that the previously mentioned studies focused on methods to improve the adhesion of fresh resin to polymerized, contaminated and aged resins. The adhesion between a resin luting agent and the core material still needs further assessment. For a precise indication of the surface conditioning for composite cores before crown cementation, it is relevant that the composite used for coronal reconstruction is exposed to moisture and temporary cementation. Therefore, the current study assessed the influence of different surface conditioning methods for composite resin core and thermocycling on the bond strength to a resin luting agent.

\section{MATERIAL AND METHODS}

Figure 1 presents the composition, trade name and manufacturer of the materials used in the present study.

A cubic metal pattern $(8 \times 8 \times 4 \mathrm{~mm})$ was molded with silicon (Silibor, Artigos Odontológicos Clássico, São Paulo, SP, Brazil) and the mold was used to produce 80 standardized composite blocks (Opallis, FGM, Joinville, SC, Brazil). The composite used is recommended for direct core fabrication. Half of the blocks were made with A4 shade and the other half was made with $B 1$ shade in order to distinguish them better. The composite was incrementally inserted into the mold and each increment was light polymerized (XL 3000, 3M ESPE, St Paul, MN, USA) for $40 \mathrm{~s}$. The last increment was light polymerized under a glass plate. The block was then removed from the mold and each face was additionally light polymerized for $40 \mathrm{~s}$. The top surface (cementation surface) of all blocks was ground with 120-grit silicon carbide paper, using a polishing machine and under water cooling. This grit size correlates to a coarse diamond bur (approximately $162 \mu \mathrm{m}$ ), which is commonly used for dental preparations ${ }^{11}$. All blocks were aged by

\begin{tabular}{|c|c|c|}
\hline Material & Trade name and manufacturer & Composition \\
\hline Microhybrid composite resin & Opallis (FGM, Joinville, Brazil) & $\begin{array}{c}\text { Bis-GMA monomers, BisEMA, TEGDMA, } \\
\text { UDMA, camphorquinone, co-initiator, silane, } \\
\text { silanized barium-aluminum silicate glass, } \\
\text { pigments. }\end{array}$ \\
\hline Temporary luting agent & $\begin{array}{c}\text { RelyX Temp (3M ESPE, São Paulo, } \\
\text { Brazil) }\end{array}$ & $\begin{array}{c}\text { Resin, reaction products with acrylic acid, } \\
\text { nonanoic acid, silane treated silica. }\end{array}$ \\
\hline $\mathrm{Phosphoric} \mathrm{acid}_{\mathrm{SiO}_{2} \text { particles }}$ & Condac 37 (FGM, Joinville, Brazil) & 37\% Ortophosphoric acid. \\
\hline $\mathrm{Al}_{2} \mathrm{O}_{3}$ powder & Cojet-Sand (3M/ESPE, Seefeld, \\
\hline Silane & (Polidental, Sano Paulo, Brazil) & $\begin{array}{c}\text { Silica-coated alumina particles } \\
\text { (particle size 30 } \mu \mathrm{m} \text { ) }\end{array}$ \\
\hline Prosil (FGM, Joinville, Brazil) & $\begin{array}{c}\text { Aluminum oxide. } \\
\text { 3-Metacriloxipropiltrimetoxisilane, } \\
\text { ethanol, water. }\end{array}$ \\
\hline Two-step light cure adhesive & Ambar (FGM, Joinville, Brazil) & $\begin{array}{c}\text { Diurethane dimethacrylate, silane treated } \\
\text { silicondioxide, camphorquinone, ethyl } \\
\text { 4-dimethylaminobenzoate, ethanol. }\end{array}$ \\
\hline Dual cure luting composite & Allcem (FGM, Joinville, Brazil) & $\begin{array}{c}\text { Paste of dimethacrylates monomers, inorganic } \\
\text { fillers, initiators, stabilizers, pigments, BisEMA, } \\
\text { TEGDMA, Bis-GMA, benzoylperoxide. }\end{array}$ \\
\hline
\end{tabular}

Figure 1- Materials used in the study 
5,000 thermocycles in water, with bath times of 30 $\mathrm{s}$ in $5^{\circ} \mathrm{C}$ and $55^{\circ} \mathrm{C}$, with a transfer time of $2 \mathrm{~s}$. A thin layer of provisional cement (RelyX Temp, 3M ESPE, Seefeld, BY, Germany) was then applied to the cementation surface and left for $24 \mathrm{~h}$. The cement was removed using manual instruments, and the surface was cleaned with pumice using a low speed hand-piece. These procedures simulate the clinical situation in which the core is built up in composite (generally anchored by a fiber post), followed by preparation with diamond burs, cementation of a provisional restoration and cleansing before final cementation of the crown (metal-free or metalceramic restorations).

After aging, the composite blocks were randomly assigned into five groups, according to the surface treatment performed before cementation:

NT - No treatment (control group);

SP - Grinding with 120-grit silicon carbide paper (Buehler, Lake Bluff, IL, USA) in a polishing machine (Ecomet, Buehler, Lake Bluff, IL, USA) at 400 rpm with water irrigation;

AC - Etching with $37 \%$ phosphoric acid (Condac 37, FGM, Joinville, SC, Brazil) for $15 \mathrm{~s}$, followed by washing with air-water spray and drying;

SC - Tribochemical silica coating: air-abrasion with $30 \mu \mathrm{m} \mathrm{SiO}$, particles (Cojet-Sand, 3M ESPE, Seefeld, Germany), followed by silanization (Prosil, FGM, Joinville, SC, Brazil);

$\mathrm{AO}$ - Sandblasting with $50 \mu \mathrm{m} \mathrm{Al}_{2} \mathrm{O}_{3}$ powder (Polidental, São Paulo, Brazil) and silane application (Prosil, FGM).

For groups SC and AO, air-abrasion was performed with a microetcher (Microjato, Bioart, São Carlos, SP, Brazil) at a distance of $10 \mathrm{~mm}$ with a pressure of 2.8 bar for $4 \mathrm{~s}$.

All groups received a layer of photo-activated adhesive resin (Ambar, FGM, Joinville, SC, Brazil) after the surface treatment, applied according to the manufacturer's recommendations.

Two composite blocks presenting the same surface treatment (each of a shade) were cemented using a dual-cured Bis-GMA based resin cement (Allcem, FGM, Joinville, SC, Brazil). The base and catalyst pastes of the resin cement were mixed and applied onto the treated surface of one block. The other block cemented to the first and a $750 \mathrm{~g}$ load was applied to the assembly during cement cure. Excess cement was removed and each face was light polymerized for $40 \mathrm{~s}$. After $5 \mathrm{~min}$, the cemented blocks were stored in distilled water at $37^{\circ} \mathrm{C}$ for $24 \mathrm{~h}$.

Preparation of the specimens for microtensile testing

The composite block sets were embedded in acrylic resin (JET, Artigos Odontológicos Clássico, São Paulo, SP, Brazil) and attached to a sectioning machine (LabCut 1010, Extec, Enfield, NH, USA). A diamond saw was used under constant water cooling to cut the blocks in the $x$ and $y$ axes. The final specimens had the following characteristics: bar shaped with a quadrangular non-trimmed interface, an adhesive area of approximately 1 $\mathrm{mm}^{2}$, and length of $8 \mathrm{~mm}$. The specimens of the periphery were discarded.

Half of the specimens from each block were immediately $\mu$ TBS tested (dry groups), while the other half was subjected to storage in distilled water at $37^{\circ} \mathrm{C}$ for 6 months and thermocycled for 12,000 cycles in water, with bath times of $30 \mathrm{~s}$ in $5^{\circ} \mathrm{C}$ and $55^{\circ} \mathrm{C}$, with an intermediate pause of $2 \mathrm{~s}$ (TC groups). Thus, 10 experimental groups were obtained, considering 5 surface treatments and 2 storage conditions (with and without aging).

\section{Microtensile bond strength test ( $\mu$ TBS)}

Before testing, the area of the bonding interface of the specimens was measured using a digital caliper (Starrett, Itu, SP, Brazil) to calculate the adhesive area. The ends of each specimen were fixed to the flat grips of the $\mu$ TBS device with cyanoacrylate gel adhesive (Suprabond Gel, Suprabond do Brasil, São Paulo, SP, Brazil). The device was attached to a universal testing machine (EMIC DL-2000, EMIC, São José dos Pinhais, PR, Brazil) and loaded in tensile at a cross-head speed of $1 \mathrm{~mm} / \mathrm{min}$. The adhesive area remained free and perpendicular to the load direction until failure of the specimen.

The bond strength was calculated using the formula: $\sigma=F / A$, where " $\sigma$ " is the bond strength (MPa), " $F$ " is the load required for specimen failure $(\mathrm{N})$, and " $\mathrm{A}$ " is the adhesive area of the specimen $\left(\mathrm{mm}^{2}\right)$.

\section{Failure mode analysis}

After $\mu$ TBS testing, the specimens were examined using a stereomicroscope (Discovery V20, Carl-Zeiss, Göttingen, Germany) at a magnification of 100x. The different shades of the composites facilitated examination. The failure types were classified as adhesive (between cement and composite), predominantly adhesive (between cement and composite, reaching the composite bulk or cement) or cohesive (inside the composite bulk, not reaching cement). Some specimens were also observed using a Scanning Electron Microscope SEM (Inspect S50, FEI, Eindhoven, Netherlands).

\section{Data analysis}

The bond strength data was analyzed by repeated measures two-way analysis of variance (ANOVA) and Tukey's and Sidak's post hoc tests $(\alpha=0.05)$. The experimental units were the composite blocks $(n=8)$. 


\section{Qualitative analysis}

Ten additional composite blocks received the experimental surface treatments $(n=2)$. These blocks were analyzed using a SEM. The specimens were analyzed under low vacuum with a magnification of $1000 x$ to observe the surface patterns created by the treatments.

\section{RESULTS}

Premature failures during specimen preparation (mainly during cutting) occurred for groups NT, SC and AO (Table 1). These specimens were discarded and not considered in the statistical analysis.

All groups presented some cohesive failures of the composite. The highest percentage of cohesive failures occurred in group SP, whereas the lowest percentage occurred in group AC (Table 1). Data

Table 1- Percentage of pre-test and cohesive failures

\begin{tabular}{cccccc}
\hline $\begin{array}{c}\text { Surface } \\
\text { treatments }\end{array}$ & $\begin{array}{c}\text { Specimens after } \\
\text { cutting }\end{array}$ & Pre-test failures & $\begin{array}{c}\text { Tested } \\
\text { specimens }\end{array}$ & \multicolumn{2}{c}{ Cohesive failures } \\
\hline No treatment (NT) & 113 & $16(14.16 \%)$ & 97 & $4(8.00 \%)$ & $1(2.13 \%)$ \\
\hline Sandpaper (SP) & 96 & $0(0.00 \%)$ & 96 & $18(40.91 \%)$ & $13(25.00 \%)$ \\
\hline Acid (A) & 102 & $0(0.00 \%)$ & 102 & $2(3.85 \%)$ & $1(2.00 \%)$ \\
\hline $\begin{array}{c}\text { Silica Coating } \\
\text { (SC) }\end{array}$ & 114 & $7(6.14 \%)$ & 107 & $5(9.62 \%)$ & $6(10.91 \%)$ \\
Aluminum Oxide & 137 & $12(8.76 \%)$ & 125 & $5(7.81 \%)$ & $21(34.43 \%)$ \\
\hline
\end{tabular}

Table 2- Mean \pm SD of $\mu$ TBS values (MPa) for each surface treatment in dry and thermocycled conditions and Sidak's multiple comparisons test for each surface treatment (MPa) (SD=standard deviation)

\begin{tabular}{ccccc}
\hline Surface treatments & Dry & TC & $\begin{array}{c}\text { Mean difference } \\
\text { (Dry-TC) }\end{array}$ & P value (Dry-TC) \\
\hline Sandpaper (SP) & $58.02 \pm 7.74^{\mathrm{A}}$ & $45.13 \pm 5.96^{\mathrm{a}}$ & 12.89 & $0.0479^{* *}$ \\
Aluminum Oxide (AO) & $47.29 \pm 9.44^{\mathrm{AB}}$ & $38.43 \pm 10.16^{\mathrm{a}}$ & 8.860 & 0.2990 \\
Silica Coating (SC) & $44.11 \pm 7.87^{\mathrm{AB}}$ & $32.14 \pm 7.41^{\mathrm{a}}$ & 11.98 & 0.0759 \\
No treatment (NT) & $40.24 \pm 24.52^{\mathrm{B}}$ & $33.74 \pm 6.80^{\mathrm{a}}$ & 6.503 & 0.6216 \\
Acid (A) & $40.67 \pm 10.09^{\mathrm{B}}$ & $32.24 \pm 6.52^{\mathrm{a}}$ & 8.431 & 0.3495 \\
\hline
\end{tabular}

*The same superscript letters indicate no significant differences in columns (Tukey's test, $\alpha=0.05$ )

${ }^{* *}$ Only the SP group showed statistical difference between dry and thermocycling groups

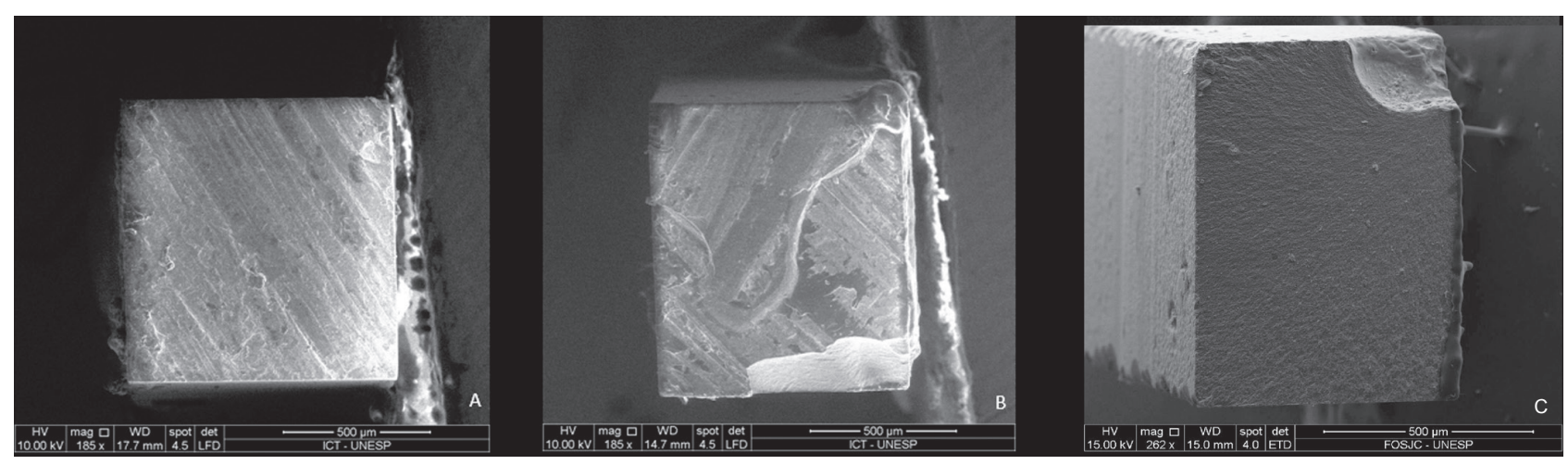

Figure 2- A) Scanning electron microscopy (SEM) image of an adhesive failure. Note the surface pattern with grooves made by the first polishing with sandpaper to simulate the initial preparation of the resin. All of the groups showed this pattern; B) SEM image of a predominantly adhesive failure. The surface pattern created by sandpaper can be seen; C) SEM image of a cohesive failure. Note that the surface pattern created by sandpaper is smoother in this type of failure 

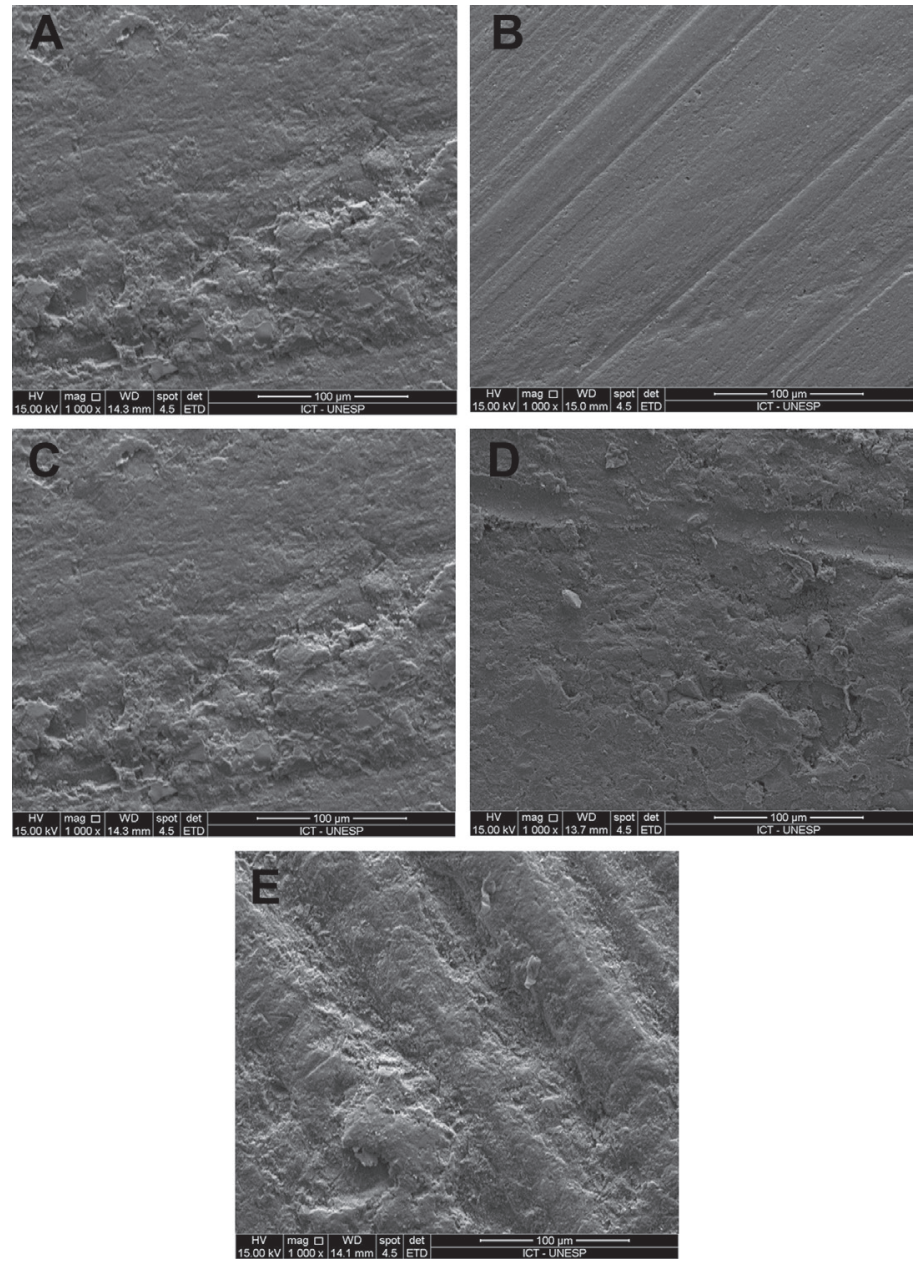

Figure 3- Surface patterns created by the surface conditionings: A) NT; B) SP; C) AC; D) SC; E) AO

from specimens with cohesive failures was not considered in the statistical analysis, since they did not represent a bond failure at the adhesive interface. The failure types can be seen in Figure 2 .

Repeated measures two-way ANOVA revealed that the $\mu$ TBS was significantly affected by the surface treatment $(p=0.007)$ and thermocycling $(p=0.000)$. There was no significant interaction between the two factors $(p=0.867)$.

Tukey's test was used to separately compare the surface treatments under dry and thermocycled conditions (Table 2). Under dry conditions, SP presented higher bond strength than NT (mean difference $=17.78 \mathrm{MPa} ; \mathrm{p}=0.015$ ) and $\mathrm{AC}$ (mean difference $=17.35 \mathrm{MPa} ; p=0.019$ ) did, whereas all the other groups were statistically similar. For the thermocycled groups, all surface treatments were statistically similar. Sidak's test compared dry and TC groups for each surface treatment (Table 2). When dry and TC groups were compared for each surface treatment, only SP group showed statistical difference.

Figure 3 presents micrographs of the topographic patterns created by the treatments. Except for SP, which showed a more regular surface, all patterns were similar.

\section{DISCUSSION}

It is often necessary to bond new composite to a composite that may have been exposed in the oral environment. This situation occurs when repairing old composites and luting resin bonded restorations if the underlying preparation was previously exposed. When luting inlays or onlays in posterior teeth, a considerable percentage of the restoration may be made of old composite that was exposed to the oral environment ${ }^{20}$. Thus, the choice of surface treatment of a composite resin core is essential for the long-term success of dental prosthetic treatment in terms of adhesion. The surface conditioning of the aged composite surface is necessary when new composite is added. Under no treatment, nearly no bond occurs between the materials ${ }^{10}$. According to our results, the use of a diamond bur that delivers the same roughness as \#120-grit sandpaper, associated with the application of an adhesive before luting, seems to be an appropriate surface treatment.

The adhesion of a fresh composite to an old one is clinically viable ${ }^{15}$. Without an adhesive, the new hydrophobic composite adheres poorly to the water-saturated old composite 22,27 . The chemistry 
of the adhesive matrix is more important than the chemistry of the matrix of the fresh composite resin ${ }^{30}$. In this study, the adhesive was applied to all groups because it is clinically mandatory, and the luting processes often include dentin and enamel substrates besides the aged composite ${ }^{30}$. However, the use of just an adhesive may not be chemically compatible with the exposed fillers of an aged resin ${ }^{9}$. The cohesive strength of a microhybrid resin is about $25.8 \mathrm{MPa}^{22}$. Although there is no consensus, the clinically required bond strength is estimated to be 20-22 $\mathrm{MPa}^{15}$, therefore, it can be concluded that the adhesive layer alone is enough to achieve adequate bond strength because the lower bond strengths obtained in this study were higher than $22 \mathrm{MPa}$.

The aging process attempts to reproduce hydrolytic degradation in the resin matrix that occurs in the oral environment ${ }^{18}$. There are many ways for aging a composite that simulate the clinical setting. In the current study, we used 5,000 thermal cycles and the application of a thin provisional cement layer. Other studies have used a saline solution ${ }^{6}$, citric acid ${ }^{18,23}$ and a sodium chloride solution ${ }^{22}$. The storage in water at $37^{\circ} \mathrm{C}$ that has been reported in the literature lasted nine days ${ }^{24}, 20$ days $^{2,10}$, one month $^{9}$, two months ${ }^{3,27}$ and six months ${ }^{4}$. Water exposure caused an increase in surface roughness ${ }^{23}$, which did not affect the repair bond strength ${ }^{9}$. It also causes swelling rather than matrix degradation, because filler exposure after water storage hardly increases ${ }^{23}$. The composite saturation with water decreases the free radicals available and capable of chemically reacting with a fresh composite ${ }^{24}$. Additionally, thermal variations can result in resin matrix degradation, leading to exposure of the underlying filler particles and increased surface roughness. This increased roughness results in microcrack formation and/or failure of the matrix/ filler interfacial bonds ${ }^{23}$. Thermocycling is an association of hydrolytic and thermal degradation ${ }^{3}$. However, there is no consensus in the literature detailing the most suitable method for aging composite resin. Thermocycling has been used in other studies ${ }^{15,18,19,23}$ to simulate temperaturerelated breakdown by repeated sudden temperature changes $^{3}$, as performed in the present study. The provisional cement was used to simulate the real clinical scenario before the luting process.

Mechanical interlocking is important for the bond strength of the aged/fresh composite, and is assumed to play a major role in composite repair ${ }^{2}$. This mechanical bonding is more effective than the use of only chemical treatments ${ }^{30}$. Mechanical roughening devices produce micro-retentions that enhance the bond strength, although there is a significant interaction between mechanical and adhesive treatments ${ }^{22}$, therefore, the present study applied the adhesive to the mechanically roughened groups. The mechanical surface treatments used in this study were air abrasion with aluminum oxide, silica coating and sandpaper grinding.

Traditionally, dentists have been trained to "freshen up" the aged resin by grinding away the superficial layer ${ }^{20}$. The use of a sandpaper, as in the present study, mimics the roughness produced by a coarse diamond bur ${ }^{11}$. The best surface treatment in this study was noted when the specimens were subjected to the grinding with sandpaper, although other studies have shown that grinding a composite surface decreases the bond strength due to filler exposure ${ }^{30}$, the formation of smear debris that interferes in the proper penetration of the adhesive monomers ${ }^{9}$ and irregular surface roughness 22,24 . Moreover, other authors have shown that grinding with a diamond bur improves the bond strength between fresh and aged resins $s^{2,4,30}$. The qualitative analysis showed that the grinding treatment removed the old resin layer, showing a new pattern that was less rough and most like a new resin. Surface treatment with a diamond bur with a proper adhesive agent is a simple, costeffective procedure ${ }^{30}$ and does not require the use of additional materials or instrumentation ${ }^{2}$.

The bond strengths of $\mathrm{AO}$ and SC were similar (Table 2), which was likely a result of the same surface roughness produced by these treatments (Figure 3$)^{24}$. The AO treatment can roughen the surface, removing parts of the soft resin matrix, and creating superficial grooves, pits and depressions ${ }^{2}$. Some authors have found greater bond strengths with the use of $50 \mu \mathrm{m}$ aluminum oxide ${ }^{6}$. The fine diamond bur (for finishing) has particles with the same size of the aluminum oxide particles used in this study ${ }^{6}$. However, the present study simulated grinding with a coarse grain bur, with a greater particle size. The superficial roughness created with air abrasion in the AO and SC groups was lower than in the grinding group (SP), which was different from the NT group.

The tribochemical silica coating was not able to create bond strengths comparable to those observed in fresh resin or with the use of other treatments ${ }^{22,23}$. In this study, the SC group showed bond strengths similar to all groups. However, another study showed that silica coating could provide higher bond strength values when compared to sandblasting with aluminum oxide ${ }^{18}$. The incorporation of silica particles was not seen in $\mathrm{SEM}^{22}$, which may explain the similarity to $\mathrm{AO}$ results. The SC treatment requires the use of a rubber dam to avoid damage to the periodontium and particle inhalation by the patient.

The application of silane enhances the wetting of a surface for the bonding agent ${ }^{14}$ and chemical bonding with the exposed fillers on the surface after 
mechanical treatment ${ }^{9}$. However, the specific effect of the coupling agent could not be determined in our study because it was not an isolated factor, as it was used in both $\mathrm{AO}$ and $\mathrm{SC}$ groups.

Although the use of acid does not require an additional device in the dental practice, such as chair-side air abrasion equipment ${ }^{18}$, surface treatment with $37 \%$ phosphoric acid and an adhesive should not be used alone in aged resin ${ }^{16}$. This type of etching did not significantly change the morphological pattern of an aged resin and its action is limited to a superficial cleaning effect ${ }^{9}$, but it can activate the reactivity between a silica surface and silane ${ }^{14}$. Mechanical treatments such as grinding with diamond bur or abrasion are needed ${ }^{16}$ before using an acid. In agreement with our results, there was no difference between the control group and etching with phosphoric acid surface treatment ${ }^{2}$. Anyway, etching can be mandatory in all cases in which there is dentin remnant ${ }^{2}$, which depends on the type of the adhesive system.

Irrespective of surface treatment, thermocycling reduces the bond strength after the luting process ${ }^{6,8}$. This type of aging represents a more challenging scenario for bond strength ${ }^{18}$. It was assumed that the lower bond strength was related to the adhesive layer, because hydrolytic instability of the adhesive results in degradation and water sorption ${ }^{6,8}$. In spite of that, only the SP group showed significantly lower bond strength after thermocycling. This result is probably due to the inadequate penetration of the adhesive monomers after this type of treatment, resulting in the formation of smear debris ${ }^{9}$.

The SP group showed the best results of bond strength, but also presented more cohesive failures. Some authors argue that the strength in the interface exceeds the cohesive strength of the aged material ${ }^{20,23,27}$. The incidence of cohesive failures may help to predict bond stability ${ }^{19}$. It is difficult to determine the failure mode in sticks of similar resin materials ${ }^{15}$. Thus, different resin shades were used in the current study. However, it was not always possible to identify if the failure was adhesive or predominantly adhesive, although cohesive failures were clearly seen and were not considered in the statistical analysis. Pre-test failures occurred during specimen preparation and after thermocycling, but these specimens were not considered in the analyses.

The ease of using diamond burs and the greater damage produced on the surface by the other mechanical methods suggest that it is preferable to roughen the surface of a core material, even though one must be careful with the internal misfit of the restoration due to excessive grinding. An adhesive layer should also be applied before the luting process.

Based on the results of this in vitro study, a composite core should be treated before adhesive cementation of an indirect restoration, and the best treatment appears to be roughening the composite core with a diamond bur-like instrument, but this method did not produce superior bond strength after aging. In terms of bond stability, aging by thermocycling tends to reduce the bond strength between composite and resin cement.

\section{ACKNOWLEDGEMENT}

The authors acknowledge FGM for the donation of the materials used in this study.

\section{REFERENCES}

1- Attia A, Lehmann F, Kern M. Influence of surface conditioning and cleaning methods on resin bonding to zirconia ceramic. Dent Mater. 2011;27:207-13.

2- Bonstein T, Garlapo D, Donarummo J Jr, Bush PJ. Evaluation of varied repair protocols applied to aged composite resin. J Adhes Dent. 2005; 7:41-9.

3- Brendeke J, Ozcan M. Effect of physicochemical aging conditions on the composite-composite repair bond strength. J Adhes Dent. 2007; 9:399-406.

4- Celik EU, Ergücü Z, Türkün LS, Ercan UK. Tensile bond strength of an aged resin composite repaired with different protocols. J Adhes Dent. 2011;13:359-66.

5- Choi Y, Pae A, Park EJ, Wright RF. The effect of surface treatment of fiber-reinforced posts on adhesion of a resin-based luting agent. J Prosthet Dent. 2010;103:362-8.

6- Costa TR, Ferreira SQ, Klein-Júnior CA, Loguercio AD, Reis A. Durability of surface treatments and intermediate agents used for repair of a polished composite. Oper Dent. 2010;35:231-7.

7- Dietschi D, Duc O, Krejci I, Sadan A. Biomechanical considerations for the restoration of endodontically treated teeth: a systematic review of the literature, Part II (Evaluation of fatigue behavior, interfaces, and in vivo studies). Quintessence Int. 2008;39:117-29.

8- El-Askary FS, El-Banna AH, van Noort R. Immediate vs delayed repair bond strength of a nanohybrid resin composite. J Adhes Dent. 2012;14:265-74.

9- Fawzy AS, El-Askary FS, Amer MA. Effect of surface treatments on the tensile bond strength of repaired water-aged anterior restorative micro-fine hybrid resin composite. J Dent. 2008;36:969-76.

10- Jafarzadeh Kashi TS, Erfan M, Rakhshan V, Aghabaigi N, Tabatabaei FS. An in vitro assessment of the effects of three surface treatments on repair bond strength of aged composites. Oper Dent. 2011;36:608-17.

11- Kim JW, Covel NS, Guess PC, Rekow ED, Zhang Y. Concerns of hydrothermal degradation in CAD/CAM zirconia. J Dent Res. 2010;89:91-5.

12- Kimyai S, Mohammadi N, Navimipour EJ, Rikhtegaran S. Comparison of the effect of three mechanical surface treatments on the repair bond strength of a laboratory composite. Photomed Laser Surg. 2010;28(Suppl 2):S25-30.

13- Li J. Effects of surface properties on bond strength between layers of newly cured dental composites. J Oral Rehabil. $1997 ; 24: 358-60$.

14- Loomans BA, Cardoso MV, Roeters FJ, Opdam NJ, De Munck J, Huysmans MC, et al. Is there one optimal repair technique for all composites? Dent Mater. 2011;27:701-9.

15- Maneenut C, Sakoolnamarka R, Tyas MJ. The repair potential of resin composite materials. Dent Mater. 2011;27:e20-7. 
16- Melo MA, Moysés MR, Santos SG, Alcântara CE, Ribeiro JC. Effects of different surface treatments and accelerated artificial aging on the bond strength of composite resin repairs. Braz Oral Res. $2011 ; 25: 485-91$.

17- Nothdurft FP, Seidel E, Gebhart F, Naumann M, Motter PJ, Pospiech PR. Influence of endodontic posts on the fracture behavior of crowned premolars with Class II cavities. J Dent. 2008;36:287-93.

18- Ozcan M, Barbosa SH, Melo RM, Galhano GA, Bottino MA. Effect of surface conditioning methods on the microtensile bond strength of resin composite to composite after aging conditions. Dent Mater. 2007;23:1276-82.

19- Özcan M, Corazza PH, Marocho SM, Barbosa SH, Bottino MA. Repair bond strength of microhybrid, nanohybrid and nanofilled resin composites: effect of substrate resin type, surface conditioning and ageing. Clin Oral Investig. 2013;17:1751-8.

20- Padipatvuthikul P, Mair LH. Bonding of composite to water aged composite with surface treatments. Dent Mater. 2007;23:519-25.

21- Perriard J, Lorente MC, Scherrer S, Belser UC, Wiskott HW. The effect of water storage, elapsed time and contaminants on the bond strength and interfacial polymerization of a nanohybrid composite. J Adhes Dent. 2009;11:469-78.

22- Rathke A, Tymina Y, Haller B. Effect of different surface treatments on the composite-composite repair bond strength. Clin Oral Investig. 2009;13:317-23.

23- Rinastiti M, Özcan M, Siswomihardjo W, Busscher HJ. Effects of surface conditioning on repair bond strengths of non-aged and aged microhybrid, nanohybrid, and nanofilled composite resins.
Clin Oral Investig. 2011;15:625-33.

24- Rodrigues SA Jr, Ferracane JL, Della Bona A. Influence of surface treatments on the bond strength of repaired resin composite restorative materials. Dent Mater. 2009;25:442-51.

25- Schmitter M, Mussotter K, OhImann B, Gilde H, Rammelsberg $P$. Dependence of in vitro fracture strength of adhesive core buildup and crown complexes on preparation design and cementation technique. J Adhes Dent. 2008;10:145-50.

26- Sindel J, Frankenberger R, Krämer N, Petschelt A. Crack formation of all-ceramic crowns dependent on different core buildup and luting materials. J Dent. 1999;27:175-81.

27- Staxrud F, Dahl JE. Role of bonding agents in the repair of composite resin restorations. Eur J Oral Sci. 2011;119:316-22.

28- Tezvergil A, Lassila LV, Vallittu PK. Composite-composite repair bond strength: effect of different adhesion primers. J Dent. 2003;31:521-5.

29- Yavirach P, Chaijareenont P, Boonyawan D, Pattamapun K, Tunma S, Takahashi $\mathrm{H}$, et al. Effects of plasma treatment on the shear bond strength between fiber-reinforced composite posts and resin composite for core build-up. Dent Mater J. 2009;28:686-92. 30- Yesilyurt C, Kusgoz A, Bayram M, Ulker M. Initial repair bond strength of a nano-filled hybrid resin: effect of surface treatments and bonding agents. J Esthet Restor Dent. 2009;21:251-60. 